Universidad Nacional Experimental Francisco de Miranda (UNEFM). Santa Ana de Coro. Venezuela

Rosa del Rocío Pinargote-Chancay; Cristhian Toala-Suarez; Victor Plua-Chancay

DOI 10.35381/cm.v6i1.386

\title{
Medidas de prevención y promoción de la salud en Comunidades ante el 2019-nCoV
}

\section{Prevention and health promotion measures in Communities before the 2019-nCoV}

\author{
Gina Alonso-Muñiz \\ gina.alonzo@unesume.edu.ec \\ Universidad Estatal del Sur de Manabí. Jipijapa \\ Ecuador \\ https://orcid.org/0000-0003-0041-2956 \\ Rosa del Rocío Pinargote-Chancay \\ rosa.pinargote@unesum.edu.ec \\ Universidad Estatal del Sur de Manabí. Jipijapa \\ Ecuador \\ https://orcid.org/0000-0001-9899-9243 \\ Victor Plua-Chancay \\ victor.plua@unesum.edu.ec \\ Universidad Estatal del Sur de Manabí. Jipijapa \\ Ecuador \\ https://orcid.org/0000-0002-0179-6632 \\ Cristhian Toala-Suárez \\ fabyan30@hotmail.com \\ Investigador Independiente, Dialilife S.A. Quevedo \\ Ecuador \\ https://orcid.org/0000-0002-1093-4670
}

Recibido: 05 de agosto de 2020 Aprobado: 25 de octubre de 2020 


\title{
RESUMEN
}

Objetivo: Identificar las medidas de prevención y promoción de la salud ante el Covid-19 en comunidades de la zona sur de la provincia de Manabí. Metodología: de enfoque cuantitativo y una tipología descriptiva con un diseño no experimental, de campo y transaccional. La población la constituyeron 275 habitantes de las comunidades de la Zona Sur de Manabí que llenaron los formularios de las encuestas solicitadas en línea durante el periodo de junio - septiembre 2020. Conclusión: Se muestra que las personas identifican el cuadro clínico de la enfermedad, las medidas de prevención y promoción, las formas de contagio y el uso de plantas medicinales para contrarrestar según ellos, la pandemia.

Descriptores: Prevención de enfermedades; infraestructura sanitaria; epidemia por el Nuevo Coronavirus 2019; participación comunitaria (Fuente DeCS, 2020).

\begin{abstract}
Objective: Identify prevention and health promotion measures against Covid-19 in communities in the southern part of the Manabí province. Methodology: quantitative approach and a descriptive typology with a non-experimental, field and transactional design. The population was made up of 275 inhabitants of the communities of the South Zone of Manabí who filled out the forms of the surveys requested online during the period June - September 2020. Conclusion: It shows that people identify the clinical picture of the disease, the prevention and promotion measures, forms of contagion and the use of medicinal plants to counteract, according to them, the pandemic.
\end{abstract}

Descriptors: Disease prevention; health infrastructure; coronavirus infections; community participation. (Source DeCS, 2020). 


\section{INTRODUCCIÓN}

EI SARS-CoV-2 es la nueva cepa del virus causante de la enfermedad Covid-19, los primeros casos fueron detectados en diciembre de 2019 en la ciudad de Wuhan, provincia de Hubei, en China ${ }^{1}$ desde entonces se extendió rápidamente afectando a todas las regiones del mundo, incluyendo América Latina y el Caribe, a tal punto que la Organización Mundial de la Salud (OMS) el 11 de marzo de 2020 declaró a esta enfermedad como una pandemia.

Esta enfermedad presenta síntomas similares a los de la gripe, entre los que se incluyen fiebre, tos seca, disnea, dolores, molestias y una manifestación clave como lo es la pérdida del gusto y el olfato. Este virus se trasmite principalmente por medio de las gotículas emitidas por una persona infectada al hablar, toser, estornudar o respirar. Estas pequeñas microgotas al ser demasiado pesadas no pueden permanecer en el aire, por ende, caen rápidamente sobre las superficies o el suelo. Ante estas circunstancias cualquier persona que no haga uso de las medidas preventivas puede adquirir el virus si está cerca de un portador, o bien si tiene contacto con objetos o superficies contaminadas, se toca la boca, nariz o los ojos, propagándose de esta manera la infección.

La OMS recomienda como parte de las medidas de promoción de la salud se debe tener absoluto cuidado en la higiene personal, tener precauciones al toser y mantener dos metros de distancia de otras personas. Así mismo, reconoció seguir las siguientes instrucciones básicas como parte de las medidas de prevención ante la Covid-19: lavarse las manos con agua y jabón o con una solución a base de alcohol, cubrirse la nariz y la boca con la parte interna del codo o con un pañuelo al momento de toser o estornudar y evitar tocarse la zona "T" del rostro. Además mencionó que no es necesario el uso de ningún tipo de mascarilla médica si la persona no presenta síntomas pues, no hay pruebas de que su uso proteja a las personas que no están enfermas². 
Sin embargo, en la actualidad como medida de prevención todos los ciudadanos deben colocarse mascarilla para evitar el contacto con posibles personas contagiadas, es así que esta norma ha sido aplicada por la mayoría de las personas, especialmente al salir de casa. La OMS confirma que hasta el 11 de noviembre 2020 van 51,5 millones de casos de coronavirus y 1,275 muertes en el mundo. En Ecuador, el portal de noticias "EXPRESO" manifestó que el 29 de febrero de 2020 se confirmó el primer caso de Covid19 y en la actualidad el país suma 180.295 casos confirmados con pruebas PCR y 13.008 fallecidos entre confirmados y probables, de los cuales 12.042 casos confirmados PCR corresponden a la provincia de Manabí incluyendo a los habitantes de la zona sur ${ }^{3,4}$. Esto hasta el día 15 de noviembre de 2020. De tal manera que la curva de crecimiento se va actualizando diariamente.

Por otra parte, ante la llegada del Covid-19 el presidente Lenin Moreno, a través del MSP, hizo conocer a la ciudadanía los estándares dispuesto por la OMS, en el sentido de aplicar las estrategias de prevención para disminuir los contagios. Sin embargo, los resultados fueron diferentes en Ecuador, a diferencia de otros países que poseen un sistema de salud organizado y muy fortalecido en cuanto a planes de prevención y promoción de la salud, personal sanitario, equipos e insumos suficientes para satisfacer las necesidades de los pacientes que acudían en busca de un servicio de salud. De ahí, que es "necesario considerar las desigualdades que existen, tanto entre como dentro de los países, y asegurar que las estrategias de respuesta sean adecuadas a la capacidad de cada jurisdicción"5.

En ese sentido cabe mencionar que el gobierno ecuatoriano requiere de mayor soporte en cuanto a planificación de programas para enfrentar la actual pandemia e incluso alguna otra catástrofe que pudiera presentarse, donde los países pobres son los más perjudicados por la desigualdad en que viven, ante un sistema de salud carente de empoderamiento en la toma de decisiones. 
Con estos antecedentes se puede afirmar que la causa del problema no es la Covid-19 como tal, sino la insuficiente aplicación de las medidas de prevención y promoción de la salud, los patrones culturales, sociales, así como la situación económica de la población ha provocado un incremento de contagios y muertes, haciendo de esta una pandemia que azota contra la vida y la salud a nivel mundial.

Como se mencionó en líneas anteriores, pese a las medidas de prevención y promoción de la salud ya estipulada existe una multiplicación de los contagios que se acentúa también por la falta de cuidado, la asepsia y el desconocimiento sobre las medidas de prevención, generando el colapso en los establecimientos de salud y un mayor número de muertes $^{6}$. En ese sentido, los contagios se asocian a la inadecuada aplicación de las medidas preventivas, cuyo aumento en la incidencia del virus se relacionó con la reapertura de los negocios, aglomeraciones y el mal uso de la mascarilla, problema que afecta a todo Ecuador incluyendo comunidades de Paján, 24 de mayo, Montecristi y Puerto Cayo, dejando como resultado un aumento en la curva de contagios y por ende de la tasa de mortalidad.

De esta manera, la investigación se realizó con el fin de reforzar el cumplimiento de las medidas sanitaras por las personas, a través de la identificación de las mismas, ya que es notorio como en los habitantes de estas zonas y de manera general en todo el país, hay un aumento de personas infectadas, precisamente por no atender de forma correcta a las medidas básicas de prevención. De ahí que, ante la insuficiente aplicación de las medidas preventivas se presenta como objetivo general; identificar las medidas de prevención y promoción de la salud puesta en práctica frente a la pandemia por la Covid-19 en las comunidades de la zona sur de la provincia de Manabí.

En tal sentido, se propone el Modelo de Promoción de la Salud (MPS) de Nola Pender, enfermera, quien expreso que la conducta está motivada por el deseo de alcanzar el bienestar y el potencial humano. Se interesó en la creación de un modelo enfermero que diera respuestas a la forma cómo las personas adoptan decisiones acerca del cuidado 
de su propia salud ${ }^{7}$. En este contexto, dicho modelo debe ser considerado y puesto en práctica por su contenido en cuanto a promoción y prevención de la salud orientada a mejorar la conducta del cuidado de la salud, del entorno y la de los demás ${ }^{8}$. El modelo da respuestas a la forma cómo las personas adoptan decisiones acerca del cuidado de su propia salud. Es decir, que las experiencias, los patrones culturales adquiridos, el entorno y las relaciones con la familia influyen en lo que el individuo considera mejor para su cuidado. Cabe destacar, que este modelo es ampliamente utilizado por los profesionales de Enfermería, dado que permite comprender los comportamientos de las personas relacionados con la salud, a la vez, que orienta hacia una generación de conductas saludables ${ }^{9}$. En sus conceptos se ilustra la naturaleza multifacética de las personas en su interacción con el entorno y expone de forma amplia los aspectos relevantes que intervienen en el cambio de la conducta de los individuos. Pender, manifestó que se debe promover una vida saludable, puesto que es primordial e incluso antes que los cuidados, porque de ese modo se evitara el crecimiento vertiginoso de la enfermedad contribuyendo a minimizar la inversión y gastos que ello implicaría para la region 9 .

\section{MATERIALES Y MÉTODOS}

La investigación tuvo un enfoque cuantitativo y una tipología descriptiva con un diseño no experimental, de campo y transaccional. Los estudios descriptivos ${ }^{10}$ develan las características de las variables en estudio tal como se presentan en su estado natural, el mismo autor indica que los diseños no experimentales se refieren a aquellos estudios donde no existe manipulación ni alteración de las variables en estudio. Es considerada de campo ${ }^{11}$ dado que la recopilación de la información y datos se hizo a través del contacto directo con el objeto de estudio en su medio y fue calificada como transaccional porque en una sola oportunidad y momento se acopió la información. Se determinó como variable dependiente las medidas de prevención y promoción y variable independiente el 
Covid-19. Por otra parte, el corpus teórico de la información científica y otros datos relevantes fueron obtenidos de los principales periódicos online del Ecuador, así como las páginas oficiales del Ministerio de Salud Pública (MSP), la OMS, Organización Panamericana de la Salud (OPS), las bases de datos indexadas como Bvs, Pubmed, Redalyc, google académico y páginas médicas reconocidas, con la finalidad de profundizar en el tema del coronavirus (Covid-19), y las actualizaciones en la curva de crecimiento sobre los contagios; el análisis-síntesis para desarrollar el plan de acción de Enfermería.

La población para este estudio estuvo conformada por 275 habitantes de las comunidades, de los cuales 63 corresponden a personas de Paján, 84 habitantes de 24 de Mayo, 25 de Montecristi y 23 personas de Puerto Cayo, que llenaron los formularios de las encuestas en línea para determinar el nivel de conocimiento que tienen y las entrevistas a los profesionales donde expresaron sus puntos de vistas y percepciones sobre esta problemática de salud a través de la plataforma MEET, durante el periodo de junio - septiembre 2020.

\section{ANALISIS Y DISCUSION DE LOS RESULTADOS}

Los resultados del análisis de los datos obtenidos mediante la recolección de información a través de la encuesta online, se presentan en gráficos con su respectiva interpretación, en la que se destacan un alto porcentaje de coincidencias acompañadas de diferentes puntos de vista al momento de seleccionar las respuestas por los 275 sujetos investigados, de los cuales la mayoría se encuentra entre los 18 a 35 años de edad. Asimismo, se obtuvieron datos e información pertinente a través de la entrevista aplicada a los profesionales de salud por medio de la plataforma MEET, que dieron soporte a la investigación por los conocimientos teóricos y prácticos de quienes están en primera línea en la lucha contra la pandemia, todo ello, para finalmente presentar un plan de acción 


\section{CIENCIAMATRIA}

Revista Interdisciplinaria de Humanidades, Educación, Ciencia y Tecnología

Año VI. Vol. VI. N${ }^{\circ}$. Edición Especial. 2020

Hecho el depósito de ley: pp201602FA4721

ISSN-L: 2542-3029; ISSN: 2610-802X

Universidad Nacional Experimental Francisco de Miranda (UNEFM). Santa Ana de Coro. Venezuela

Rosa del Rocío Pinargote-Chancay; Cristhian Toala-Suarez; Victor Plua-Chancay

de Enfermería se estableció de acuerdo a las respuestas obtenidas mediante las técnicas aplicadas.

Gráfico 1. ¿Reconoce los síntomas que hacen parte del cuadro clínico que causa el sars-cov-2?

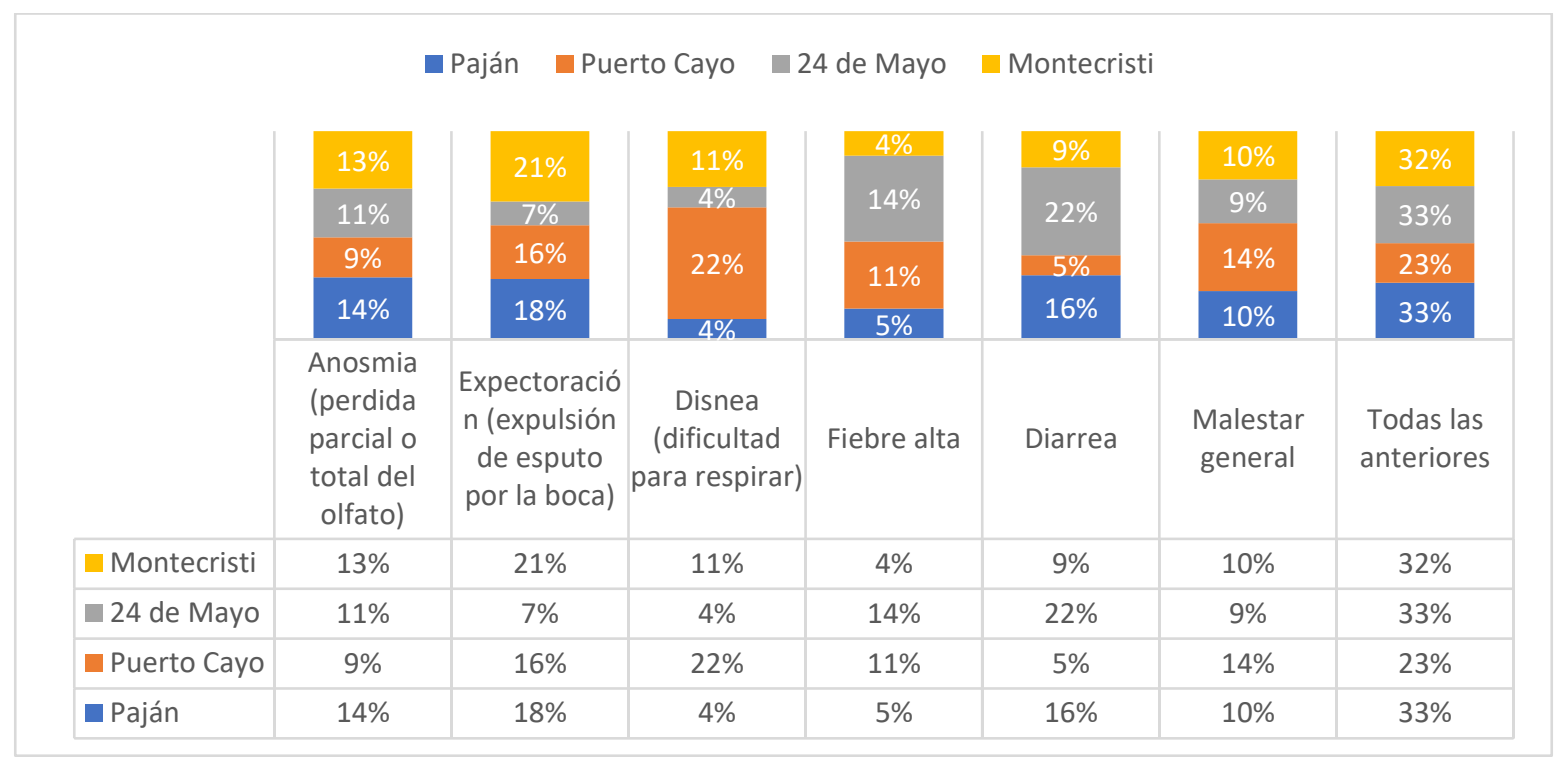

Fuente: Habitantes de Paján, 24 de Mayo, Montecristi y Puerto Cayo Elaborado por: Grupo de investigadores.

En el grafico 1, se presenta el análisis descriptivo frecuencial del reconocimiento del cuadro clínico que causa el sars-cov-2, en la misma se indica que el $33 \%$ por igual de los habitantes investigados de la comunidad 24 de Mayo y el Pajan indicaron que reconocían todos los síntomas. Seguido del $32 \%$ de la comunidad de Montecristi y un $23 \%$ de la comunidad de Puerto cayo. Asimismo, se pudo constatar que la mayor parte de los habitantes de las diferentes localidades de la zona sur de Manabí, consideran según su criterio que los síntomas como: anosmia, hipertermia, expectoración, disnea, diarrea y malestar general están asociados al cuadro clínico que causa el SARS-CoV-2. 
CIENCIAMATRIA

Revista Interdisciplinaria de Humanidades, Educación, Ciencia y Tecnología

Año VI. Vol. VI. N${ }^{\circ}$. Edición Especial. 2020

Hecho el depósito de ley: pp201602FA4721

ISSN-L: 2542-3029; ISSN: 2610-802X

Universidad Nacional Experimental Francisco de Miranda (UNEFM). Santa Ana de Coro. Venezuela

Rosa del Rocío Pinargote-Chancay; Cristhian Toala-Suarez; Victor Plua-Chancay

Grafico 2. Mecanismo de transmisión del SARS-CoV-2?

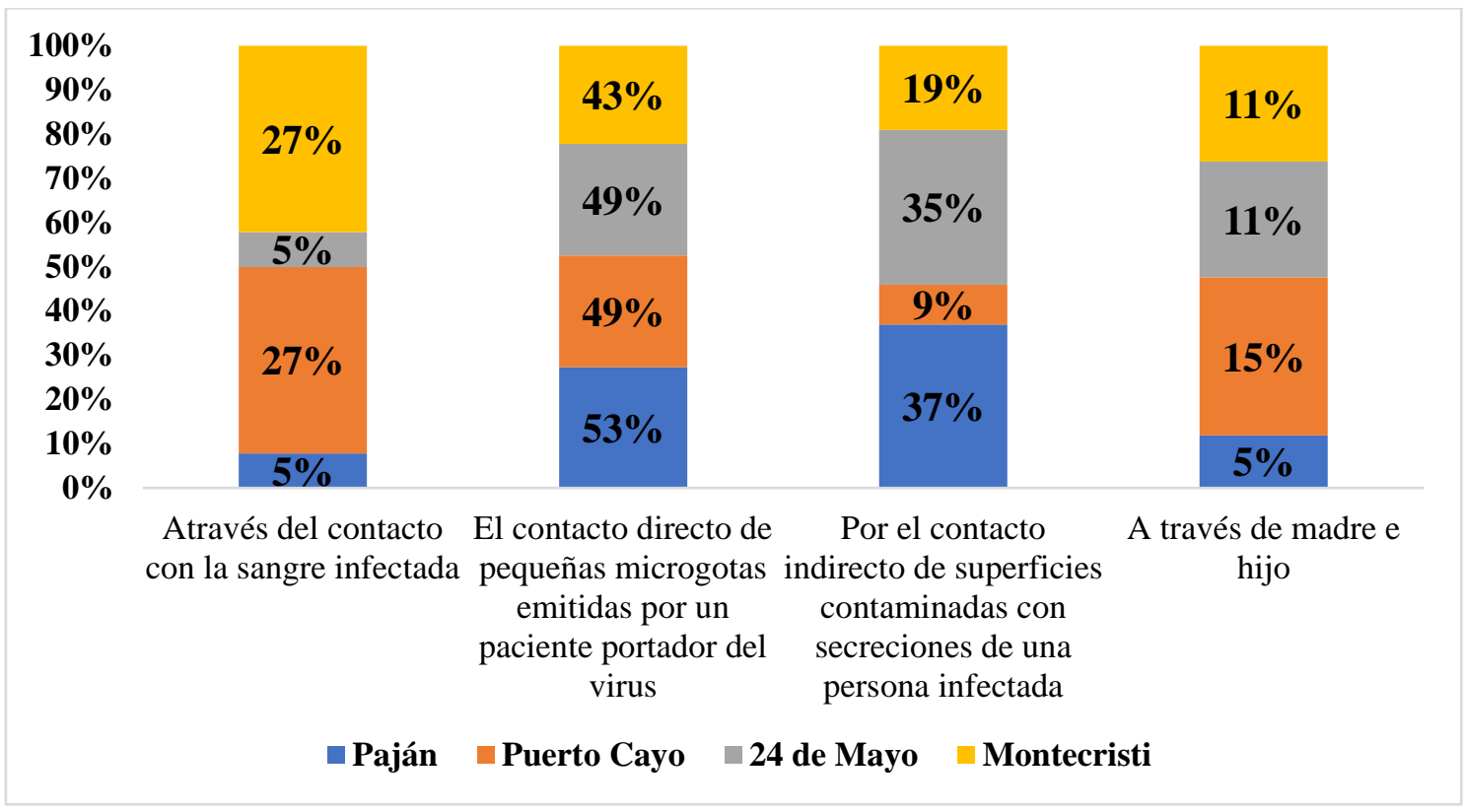

Fuente: Habitantes de Paján, 24 de Mayo, Montecristi y Puerto Cayo. Elaborado por: Grupo de investigadores.

En el grafico 2, se presenta el análisis descriptivo frecuencial de la pregunta relacionada con el mecanismo de transmisión del SARS-CoV-2, y con mayor frecuencia de un $49 \%$ por igual de los investigados en las comunidades de Puerto Cayo y 24 de Mayo, un 53\% de la comunidad del Pajan y $43 \%$ de la comunidad de Montecristi coincidieron en opinar que el mecanismo de trasmisión era el contacto directo de pequeñas microgotas emitidas por un paciente portador del virus. Seguido del 35\% y 37\% en opinión de las comunidades del 24 de Mayo y Pajan respectivamente que señalaron como mecanismo por el contacto directo por superficies contaminadas con secreciones de una persona infectada. Seguido 
CIENCIAMATRIA

Revista Interdisciplinaria de Humanidades, Educación, Ciencia y Tecnología

Año VI. Vol. VI. N${ }^{\circ}$. Edición Especial. 2020

Hecho el depósito de ley: pp201602FA4721

ISSN-L: 2542-3029; ISSN: 2610-802X

Universidad Nacional Experimental Francisco de Miranda (UNEFM). Santa Ana de Coro. Venezuela

Rosa del Rocío Pinargote-Chancay; Cristhian Toala-Suarez; Victor Plua-Chancay

por porcentajes menores de opiniones en las comunidades investigadas que indicaron la transmisión del SARS-CoV-2 por el contacto indirecto con superficies contaminadas.

Gráfico 3. Estrategias utilizadas para prevenir y evitar el contagio por el SARS-CoV-2?

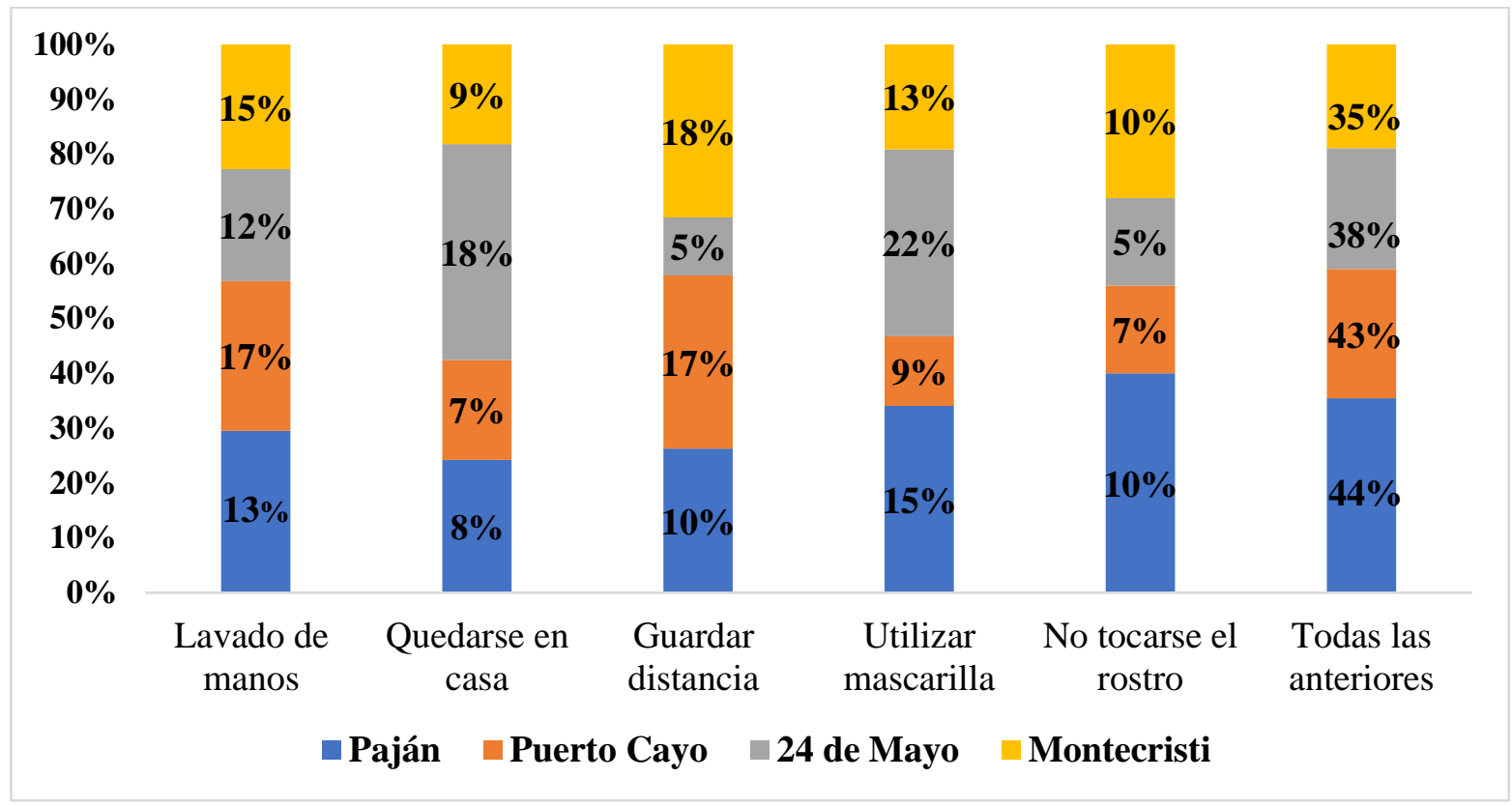

Fuente: Habitantes de Paján, 24 de Mayo, Montecristi y Puerto Cayo Elaborado por: Grupo investigador.

En el grafico 3, se indica el análisis descriptivo frecuencial del indicador Estrategias utilizadas para prevenir y evitar el contagio por el SARS-CoV-2, en la que se indica que los mayores porcentajes de opinion en las comunidades investigadas con un $44 \%$ del Pajan, 43\% Puerto Cayo, 38\% 24 de Mayo y 35\% de Montecristi consideraron aplicar todas las estrategias expuestas. Asimismo, se destaca el hecho en la cual las personas en la comunidad de Puerto Cayo consideran que el lavado de manos es la estrategia más utilizada para evitar el contagio por el SARS-CoV-2, mientras que en 24 de Mayo la 
población prefiere quedarse en casa y hacer uso de la mascarilla al salir de esta, los habitantes de Montecristi indicaron la estrategia guardar distancia. Por último, quienes habitan en Paján coinciden que no se deben tocar el rostro como medida para evitar enfermarse.

De allí que , para hacer frente a la pandemia tanto el personal de primera línea, científicos, investigadores, académicos, etc, se hace necesario establecer estrategias para contrarrestar los efectos de la enfermedad, evitar al aumento de la mortalidad y buscar la cura ante un enemigo que sigue amenazando la salud y la vida de toda la población a nivel mundial, del cual no escapa Ecuador, cuyas características de multiétnico y pluriculturalismo de comunidades indígenas, en algunas comunidades como el pueblo de Chimborazo, ante la presencia del COVID-19, determinaron sus propias medidas de cuidado prohibiendo el ingreso a personas extrañas a su comunidad, todo ello a pesar que estas comunidades viven en condiciones de precariedad y resuelven sus problemas de salud a través de sus conocimientos ancestrales, y frente a la pandemia han utilizado lo que les proporcionan sus tierras; las hojas de eucalipto, santamaría, marco y otras plantas medicinales ${ }^{12}$, que fueron para ellos la medicina que no encontraron en el sistema de salud por la deficiente capacidad para tratar y controlar una enfermedad que se salió de control. 
Gráfico 4. Medidas de prevención ante la Covid-19

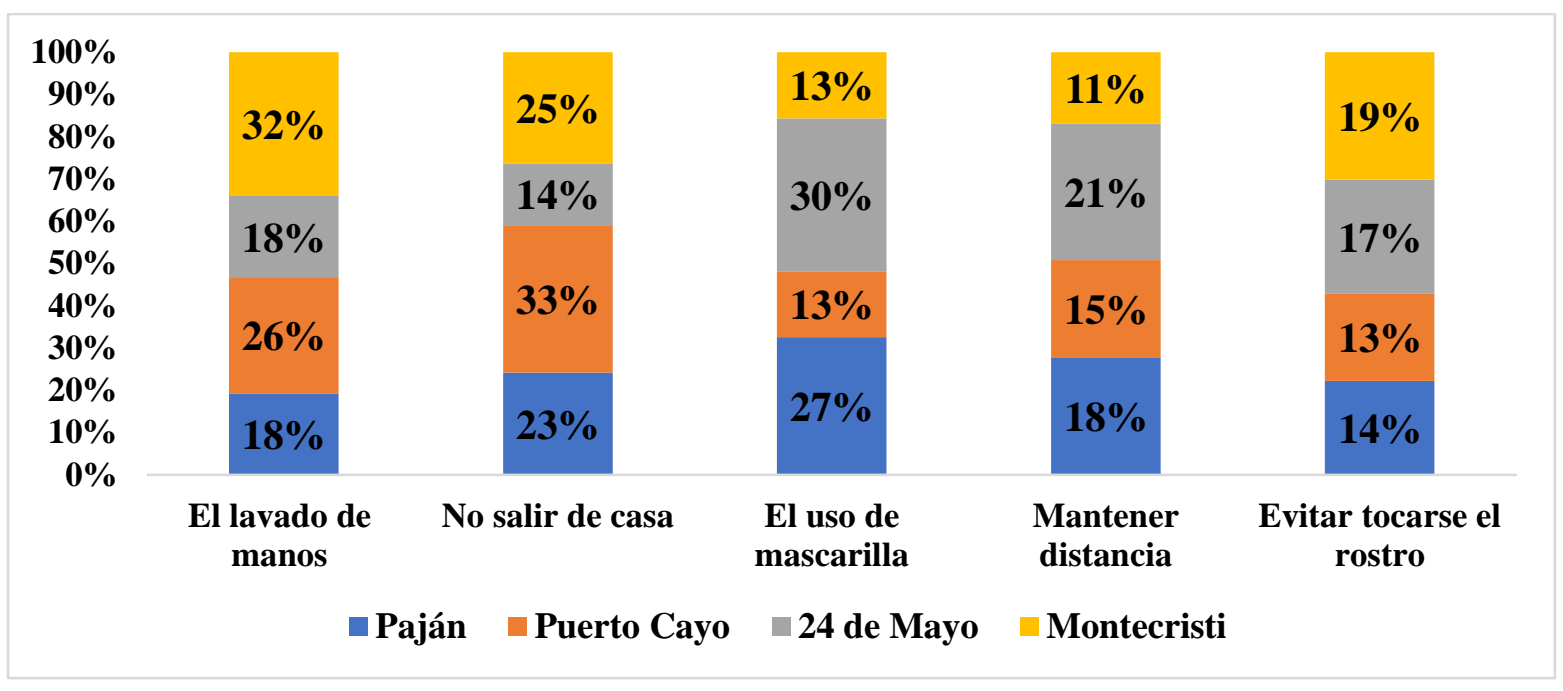

Fuente: Habitantes de Paján, 24 de Mayo, Montecristi y Puerto Cayo Elaborado por: Grupo investigador.

En el grafico 4, se indica el análisis descriptivo frecuencial de las medidas de prevención del Covid-19, y entre los porcentajes más altos de opiniones el $33 \%$ de la población de Puerto Cayo consideran no salir de casa como Medida de prevención ante la Covid-19. El $30 \%$ de la comunidad 24 de Mayo el uso de la mascarilla y el $32 \%$ de la comunidad de Montecristi el lavado permanente de las manos. Entre otras medidas, señalaron en las comunidades de Paján y Puerto Cayo el remojar el calzado con una sustancia desinfectante, así también en la comunidad de Montecristi es donde utilizan en su mayoría la desinfección con alcohol gel.

Es notorio que la mayor parte de los habitantes pertenecientes a las comunidades investigadas convienen en que se deben implementar medidas masivas de información y actividades dirigidas por organismos de control estatal y municipal hacia las personas, pues es notorio que hacen caso omiso en atender a las medidas de prevención y promoción de la salud, aspectos que según los expertos en el cuidado de la salud como médicos y enfermeras entrevistadas manifestaron que, si bien existen protocolos 
proporcionados por el MSP y el Comité de Operaciones de Emergencia Nacional (COE) para evitar el contagio, estos no se cumplen, por la falta de conocimiento y los aspectos culturales que tienen los habitantes. Sin embrago, estos mismos entrevistados manifiestan que es necesario mayor difusión y educación a la sociedad sobre el actual problema de salud pública.

Gráfico 5. Percepción de los habitantes ante el incremento de contagios por el coronavirus

\begin{tabular}{|c|c|c|c|c|}
\hline \multirow[t]{3}{*}{$\begin{array}{r}100 \% \\
\mathbf{9 0 \%} \\
\mathbf{8 0 \%} \\
\mathbf{7 0 \%} \\
\mathbf{6 0 \%} \\
\mathbf{5 0 \%} \\
\mathbf{4 0 \%} \\
\mathbf{3 0 \%} \\
\mathbf{2 0 \%} \\
\mathbf{1 0 \%} \\
\mathbf{0} \%\end{array}$} & $\begin{array}{l}29 \% \\
9 \%\end{array}$ & $\begin{array}{l}14 \% \\
36 \% \\
37 \%\end{array}$ & $\begin{array}{l}18 \% \\
28 \%\end{array}$ & $\begin{array}{l}25 \% \\
14 \% \\
10 \% \\
32 \%\end{array}$ \\
\hline & \multirow[t]{2}{*}{$\begin{array}{l}\text { A la poca importancia } \\
\text { por parte de las } \\
\text { autoridades }\end{array}$} & $\begin{array}{l}\text { A lo inconciente que } \\
\text { son las personas }\end{array}$ & $\begin{array}{c}\text { A la falta de } \\
\text { conocimiento sobre las } \\
\text { medidas de prevención } \\
\text { y pormoción de la } \\
\text { salud }\end{array}$ & $\begin{array}{l}\text { A que las personas } \\
\text { piensan que la carga } \\
\text { viral del coronavirus } \\
\text { ha disminuido }\end{array}$ \\
\hline & & Puerto Cayo & 4 de Mayo $\square$ Montecr & isti \\
\hline
\end{tabular}

Fuente: Habitantes de Paján, 24 de Mayo, Montecristi y Puerto Cayo Elaborado por: Grupo investigador.

El grafico 5, se presenta el análisis descriptivo frecuencial de la percepción de los habitantes ante el incremento de contagios por el coronavirus, donde el $46 \%$, $36 \%$ y $37 \%$ de las comunidades del Pajan, Montecristi y 24 de Mayo con mayor porcentaje de opiniones consideran que el incremento de contagios por Coronavirus se debe a la inconciencia de las personas, mientras que $43 \%$ de la comunidad de Montecristi indicaron que se debe a la poca importancia por parte de las autoridades. También se destaca, el hecho en la cual la misma comunidad del Pajan con un $32 \%$ de las opiniones la dan 
CIENCIAMATRIA

Revista Interdisciplinaria de Humanidades, Educación, Ciencia y Tecnología

Año VI. Vol. VI. N¹. Edición Especial. 2020

Hecho el depósito de ley: pp201602FA4721

ISSN-L: 2542-3029; ISSN: 2610-802X

Universidad Nacional Experimental Francisco de Miranda (UNEFM). Santa Ana de Coro. Venezuela

Rosa del Rocío Pinargote-Chancay; Cristhian Toala-Suarez; Victor Plua-Chancay

importancia a la percepción que poseen como incremento del virus a que las personas piensan que la carga viral del coronavirus ha disminuido.

Grafico 6. Medicamentos y/o plantas para prevenir o tratar las enfermedades respiratorias que causa el coronavirus.

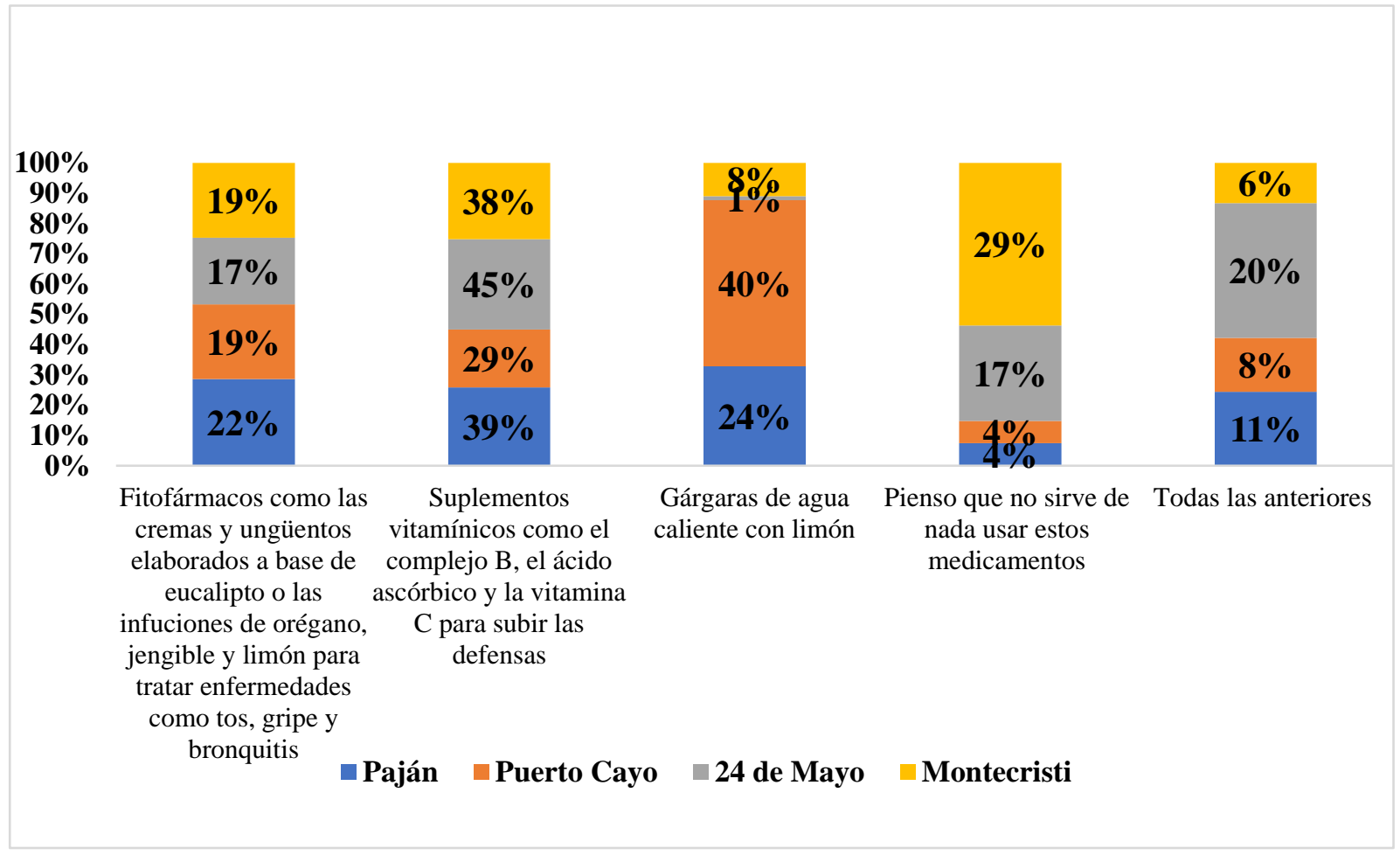

Fuente: Habitantes de Paján, 24 de Mayo, Montecristi y Puerto Cayo. Elaborado por: Grupo investigador.

En el grafico 6, se presenta el análisis descriptivo frecuencial del indicador medicamentos y/o plantas para prevenir o tratar las enfermedades respiratorias que causa el coronavirus, en la misma se indica que entre los habitantes de las comunidades investigadas, que ante el miedo de contagiarse en las casas asistenciales o centros de salud cercanos, preferían tomar infusiones como medidas de prevención ante el Covid19. Se destaca el hecho, en la cual el $45 \%$ de la comunidad del 24 de Mayo tomaban suplementos vitamínicos como el complejo $\mathrm{B}$, el calcio ascórbico y la vitamina $\mathrm{C}$ para 
subir sus defensas y el $40 \%$ de la comunidad de Puerto Cayo señalo que realizan infusiones o gárgaras a base de plantas medicinales (limón, manzanilla, orégano y eucalipto) como opción viable en ese momento. Para ello, recogían de sus siembras lo que tenían y compraban otras plantas que no se cosechan en esta región.

Posterior al análisis y discusión de los resultados obtenidos, se hace necesario que enfermería y todo el equipo de salud contribuyan al bienestar de la salud de las personas mediante un modelo de enfermería que permita tomar decisiones en relación a las formas de cuidado de la propia salud. Además, que se reconozca las experiencias personales, las conductas y patrones culturales que conllevan al individuo a tomar medidas de prevención y promoción de la salud ante la presente pandemia. En este sentido, es posible presentar el siguiente plan de acción de Enfermería como una estrategia dirigida a facilitar herramientas para mantener informado a los individuos tanto a nivel personal, familiar y comunitario, en este caso encaminado hacia los habitantes de la zona sur de Manabíí ${ }^{13}$. Este es un recurso fundamental que permite realizar un monitoreo, autoevaluación y rendición de cuentas sobre la gestión de la dirección territorial de salud a través de la realización de las actividades planificadas para cumplir con las metas propuestas $^{13}$

\section{Plan de acción de enfermería en la prevención y promoción de la salud ante las afecciones respiratorias causadas por la Covid-19}

Introducción: Atendiendo el objetivo principal del estudio el cual se enfocó en identificar las medidas de prevención y promoción de la salud puesta en práctica frente a la pandemia por la Covid-19 en las comunidades de la zona sur de la provincia de Manabí, se presenta un plan de acción de enfermería como estrategia encaminada a proveer herramientas para la prevención y promoción de la salud de las personas, familias y comunidades orientadas a proporcionar conocimientos, promover estilos de vida, 
conductas saludables y concientizar sobre la enfermedad, dando respuestas a las necesidades de los individuos en beneficio de la salud.

El plan de acción promueve al personal de Enfermería a tomar decisiones sobre los problemas que influyen en la salud, tomando como base teórica y científica el metaparadigma de Enfermería según el modelo de Nola Pender, que sin lugar a duda dan la pauta sobre cómo las personas adoptan decisiones acerca del cuidado de su propia salud. Este plan dentro de su contenido a desarrollar incluye el Proceso de Atención de Enfermería como método organizado y sistemático, que mediante sus etapas permitirá valorar los elementos que son determinantes de la salud y que desencadenan un riesgo importante ante la presencia de una pandemia que amenaza contra el bienestar y la vida. Además, que permite recoger información sobre aspectos que influyen no solo en lo fisiológico, sino también en lo social y cultural.

Los datos obtenidos en la valoración serán un fundamento para emitir un juicio enfermero que servirá para dar solución a los problemas reales o potenciales presentes en las diferentes localidades. Se incluirá los Diagnósticos de la taxonomía NANDA. Posteriormente se procede a la fase de planificación que consiste en prever los cuidados de enfermería en la prevención y promoción de la salud. Se establecerá cada uno de los cuidados que disminuyen o resuelvan el problema, en este caso las acciones que están encaminadas a orientar a las personas sobre sus patrones culturales y sociales ante el Coronavirus (Covid-19).

Por otro lado, una vez planteado esos objetivos propuestos, se continuará con la ejecución de las actividades, aquí la participación de las personas, es una prioridad con el fin de conocer aspectos débiles y fuertes de ellos, en esta etapa se pondrá en práctica el plan de cuidados e irá acompañado de enseñanza y aprendizaje tanto para los profesionales en formación como para los individuos. En la evaluación se mostrará que tan efectivo fue el proceso, si se cumple con las expectativas de los objetivos propuestos y las acciones de enfermería que tan pertinentes han sido, es decir, se corroborará el 
efecto del PAE en la prevención y promoción de la salud de los individuos, a nivel personal, familiar y comunitario.

Finalmente, el plan de acción ofrece un servicio a la comunidad con actividades de enfermería dirigidas al cuidado comunitario, donde todas las personas, serán parte del aprendizaje de conocimientos sobre la prevención y promoción ante la pandemia del Coronavirus (Covid-19).

Objetivo: Evaluar las acciones de Enfermería que intervienen en la modificación de la conducta y actitudes en la prevención y promoción de la salud.

Justificación: El plan de acción es fundamental aplicarlo porque identificará según el Modelo de Nola Pender los beneficios percibidos, la autoeficacia y será un instrumento que permitirá generar o modificar la conducta promotora de la salud. Además, con los resultados de las acciones de Enfermería se espera que los efectos sean positivos y que contribuyan a obtener conocimientos sobre el contagio de la enfermedad dando prioridad al bienestar de la salud con eficacia y eficiencia.

A los profesionales en formación les ayudará a entender progresivamente el proceso salud-enfermedad, conocimientos que servirán de apoyo a la práctica de Enfermería y contribuirá a mejorar la calidad de los cuidados, la calidad de vida, dando fortaleza y fundamento a la disciplina y a su quehacer de manera objetiva hacia los intereses de los profesionales y las necesidades de los individuos y el aprendizaje de los estudiantes en relación a la prevención y promoción de enfermedades.

Cuadro 1: Esquematización del plan de acción de enfermería en la prevención y promoción de la salud ante las afecciones respiratorias causadas por la Covid-19.

\begin{tabular}{|l|l|l|l|}
\hline Meta & Estrategias & Actividades & Responsables \\
\hline
\end{tabular}


CIENCIAMATRIA

Revista Interdisciplinaria de Humanidades, Educación, Ciencia y Tecnología

Año VI. Vol. VI. N 1 . Edición Especial. 2020

Hecho el depósito de ley: pp201602FA4721

ISSN-L: 2542-3029; ISSN: 2610-802X

Universidad Nacional Experimental Francisco de Miranda (UNEFM). Santa Ana de Coro. Venezuela

Rosa del Rocío Pinargote-Chancay; Cristhian Toala-Suarez; Victor Plua-Chancay

\begin{tabular}{|c|c|c|c|}
\hline $\begin{array}{l}\text { Concientizar a las } \\
\text { familias } \\
\text { comunidades sobre } \\
\text { las repercusiones del } \\
\text { Coronavirus (Covid- } \\
\text { 19) en el contexto del } \\
\text { bienestar físico, } \\
\text { mental y social. }\end{array}$ & $\begin{array}{l}\text { Trabajo en equipo, } \\
\text { Conferencias } \\
\text { virtuales por } \\
\text { personal de salud } \\
\text { dirigidas a las } \\
\text { familias } \\
\text { comunidades }\end{array}$ & $\begin{array}{l}\text { Elaborar material } \\
\text { digital y físico para } \\
\text { mostrar y entregar } \\
\text { a las familias y } \\
\text { comunidades }\end{array}$ & $\begin{array}{l}\text { Los } \\
\text { investigadores }\end{array}$ \\
\hline $\begin{array}{l}\text { Proporcionar } \\
\text { conocimientos } \\
\text { sobre las } \\
\text { formas de prevenir la } \\
\text { enfermedad de la } \\
\text { Covid-19 haciend } \\
0 \\
\text { énfasis en el uso de la } \\
\text { mascarilla. }\end{array}$ & $\begin{array}{l}\text { Informar por medio } \\
\text { de comunicación } \\
\text { en informativos } \\
\text { radiales y } \\
\text { televisivos de la } \\
\text { localidad. }\end{array}$ & $\begin{array}{lr}\text { Elaborar trípticos } \\
\text { digitales, videos, } \\
\text { podcast } \\
\text { compartirlos en } \\
\text { redes sociales. }\end{array}$ & $\begin{array}{l}\text { Los } \\
\text { investigadores }\end{array}$ \\
\hline \begin{tabular}{l} 
Educar a la población \\
sobre el uso de los \\
Fitofármacos y y/o \\
plantas medicinales \\
para tratar \\
\multicolumn{4}{c}{ afeccione } \\
s respiratorias \\
causadas por la \\
Covid-19.
\end{tabular} & $\begin{array}{l}\text { Utilizar plataformas } \\
\text { en } \\
\text { línea para realizar } \\
\text { charlas virtuales }\end{array}$ & \begin{tabular}{l} 
Desarrollar videos \\
expositivos, y \\
herramientas \\
digitales tales \\
como diapositivas \\
\multicolumn{1}{c}{ para } \\
presentarlos.
\end{tabular} & $\begin{array}{l}\text { Los } \\
\text { investigadores }\end{array}$ \\
\hline $\begin{array}{l}\text { Promover los estilos } \\
\text { de vida de las } \\
\text { personas, familias y } \\
\text { comunidades ante la } \\
\text { enfermedad del } \\
\text { coronavirus (Covid- } \\
\text { 19). }\end{array}$ & $\begin{array}{l}\text { Sesiones online } \\
\text { con dirigentes de } \\
\text { las comunidades y } \\
\text { localidades }\end{array}$ & $\begin{array}{l}\text { Elaborar material } \\
\text { didáctico } \\
\text { presentarlos } \quad y \\
\text { (diapositivas). }\end{array}$ & $\begin{array}{l}\text { Los } \\
\text { investigadores }\end{array}$ \\
\hline $\begin{array}{l}\text { Generar conductas } \\
\text { saludables a las } \\
\text { personas, familias y } \\
\text { comunidades. }\end{array}$ & $\begin{array}{l}\text { Utilizar el Modelo } \\
\text { de promoción de la } \\
\text { salud de Nola } \\
\text { Pender. }\end{array}$ & $\begin{array}{lr}\text { Elaborar el } & \text { PAE } \\
\text { aplicando } & \text { como } \\
\text { referencia } & \text { los } \\
\text { conceptos } & \text { del } \\
\text { Modelo } & \text { de } \\
\text { Promoción de Nola } \\
\text { Pender. }\end{array}$ & $\begin{array}{l}\text { Los } \\
\text { investigadores }\end{array}$ \\
\hline
\end{tabular}

Fuente: Grupo investigador. 


\section{CONCLUSIONES}

Las personas de las diversas comunidades de la zona Sur de Manabí, cuentan con medios para informarse sobre el Coronavirus (Covid-19), incluso identifican la sintomatología de la enfermedad, las medidas de prevención para evitar el contagio, pero hay resistencia al cumplir con las medidas, debido a que Ecuador, como país multicultural y de diversidad étnica tiene influencia de los patrones culturales al momento de decidir sobre el cuidado de la salud. Esto prevalece desde épocas pasadas, por cuanto las enseñanzas de los ancestros, que por años se ha mantenido en lo tradicional hacen que permanezca presente al momento de tomar decisiones con respecto a curarse de una enfermedad o dolencia.

Es necesario, que el sistema de salud, antes que buscar otras formas de educar a la población, debe primero comprender las actitudes y comportamientos de una sociedad que no se olvida de sus costumbres y que mantiene preceptos contrarios a lo que posee la salud pública. Para ello, el modelo vigente de Nola Pender, es fundamental aplicarlo, al ser una herramienta útil en la prevención y promoción de la salud.

Las comunidades rurales del Ecuador han sido vulneradas en distintas esferas: en to social, en la salud, educación y alimentación, con la llegada de la pandemia se visibilizan aún más estas carencias, que no se ha resuelto y no se resolverán hasta que haya un verdadero compromiso social en beneficio de las clases menos favorecidas.

\section{FINANCIAMIENTO}

No monetaria 


\section{AGRADECIMIENTO}

A la Universidad Estatal del Sur de Manabí; por motivar el desarrollo de la investigación.

\section{REFERENCIAS CONSULTADAS}

1. Santos Sanchez N, Salas Coronado R. Características estructurales de origen, medidas de prevención, diagnóstico y posibles fármacos para prevenir y COVID19. [Origin structural characteristics, prevention measures, diagnosis and potential drugs to prevent and COVID-19] Biblioteca Nacional de Medicina. 2020 Septiembre; 25(20).

2. ORGANIZACION MUNDIAL DE LA SALUD. Disponible en: https://n9.cl/q193f

3. EXPRESO. www.expreso.ec. [Online].; Disponible en: https://n9.cl/vfq5

4. Ministerio de Salud Publica. Boletines Epidemiologicos COVID-19. [COVID-19 Epidemiological Bulletins].; 2020.

5. Lau LL H, K W. Estartegias de respuesta de COVID-19: cosniderando las desigualdades entre paises y dentro de ellos. Int J Equity Health. 2020.

6. COMITÉ DE OPERACIONES DE EMERGENCIA (COE). gestionderiesgos.gob.ec. [gestionderiesgos .gob.ec]. Disponible en: https://n9.cl/ivs95

7. Aristizabal Hoyos G, al e. El modelo de promocion de la salud de Nola Pender: Una reflexion en torno a su comprension. Enfermeria Universitaria. 2011 Mayo; 8(4).

8. Torres Contreras C. A pandemia por COVID-19: umma oportunidade para visibilizar a enfermagen em nivel internacional. Re. Gaucha Enferm. 2020.

9. Martha Raile Alligood AMT. Modelos y Teorias en Enfermeria. Septima Edicion. Septima ed. Monforte MR, editor. Barcelona: Elsevier Mosby; 2011. 
CIENCIAMATRIA

Revista Interdisciplinaria de Humanidades, Educación, Ciencia y Tecnología

Año VI. Vol. VI. N ${ }^{\circ}$ 1. Edición Especial. 2020

Hecho el depósito de ley: pp201602FA4721

ISSN-L: 2542-3029; ISSN: 2610-802X

Universidad Nacional Experimental Francisco de Miranda (UNEFM). Santa Ana de Coro. Venezuela

Rosa del Rocío Pinargote-Chancay; Cristhian Toala-Suarez; Victor Plua-Chancay

10. Méndez, A. La investigación en la era de la información: guía para realizar la bibliografía y fichas de trabajo. México, Trillas. 2008

11. Hernández, Fernández y Baptista. Metodología de la Investigación.Tercera Edición. México .Editorial Me Graw Hill.2014

12. Tuaza Castro L. El COVID-19 en las comunidades indigenas de Chimborazo, Ecuador.[ COVID-19 in the indigenous communities of Chimborazo, Ecuador] Latin AMerican and Caribbean Ethnic Studies. 2020.

13. Rueda SLF. MinSalud. Disponible en: https://n9.cl/42zvi

(C2020 por el autor. Este artículo es de acceso abierto y distribuido según los términos y condiciones de la licencia Creative Commons Atribución-NoComercial-Compartirlgual 4.0 Internacional (CC BY-NC-SA 4.0)

(https://creativecommons.org/licenses/by-nc-sa/4.0/). 